\title{
The measurement of boron isotope for geological standard materials by using MC-ICPMS
}

\author{
JINLONG MA ${ }^{1 *}$, GUANHONG ZHU ${ }^{12,}$, GANGJIAN WEI ${ }^{1}$, \\ AND LE ZHANG ${ }^{1}$ \\ ${ }^{1}$ State Key Laboratory of Isotope Geochemistry, Guangzhou \\ Institute of Geochemistry, Chinese Academy of Sciences, \\ Guangzhou 510640, China (*correspondence: \\ jlma@gig.ac.cn; hexinyue@gig.ac.cn; \\ zhuguanhong@gig.ac.cn \\ gjwei@gig.ac.cn;wangzhibing@gig.ac.cn; \\ zhangle@gig.ac.cn; zengti@gig.ac.cn; \\ ${ }^{2}$ University of Chinese Academy of Sciences, Beijing \\ 100049, China
}

Boron(B) isotope is widely used in reconstructing the $\mathrm{pH}$ value of paleocean and tracing the geological process in contential earth, such as subduction, silicate weathering process et al. High-precision of B isotope measurement is fundamental to resolve above issues, however, to date, the data of B isotope reported still exist a big difference between different labs, especially for silicate samples, which is likely resuled due to the contamination, or less $\mathrm{B}$ recovery during chemical column or B evaporation process. Here, we present a serious of geological standard materials for B isotope measurement by MC-ICPMS.

The samples were dissolved by a mixed reagents of $\mathrm{HF}+\mathrm{H} 2 \mathrm{O} 2+2 \%$ mannitol and $\mathrm{B}$ was purified by concentrated $\mathrm{HF}$ as eluent. After evaporated the above B solution to 0.1$0.2 \mathrm{~mL}$, then $\mathrm{B}$ contents were measured by ICPMS and B isotope were measured by MC-ICPMS after diluted the above B solution by Milli-Q wate to appropriate concentrations. All the samples were replicated three times including chemical column and measurements of B contents and B isotope. The data show that most samples of them are uniform in B contents and B isotope compositions within analytical error. However for these samples evaporated to dryness, the significant B was lost and B isotopes were also changed and heavy $11 \mathrm{~B}$ was preferentially evaporated, resulting in the lighter B isotope compositon in residue. In this experiment, some data of geological standard materials are consistent with data published previously, such as JB-2, JB-3, B-5 and B-8 et al, while there are also some samples show quite different data with previous data (Wei et al., 2013) , such as BHVO$2, \mathrm{AGV}-2$ and $\mathrm{W}-2$ et al. So it should be cautious to compare the data between different labs.

Reference:

G. Wei, J. Wei, Y. Liu, T. Ke, Z. Ren, J. Ma and Y. Xu, J. Anal. At. Spectrom., 2013, 28, 606-612. 